\title{
Simulation in Physiotherapy Students for Clinical Decisions during Interaction with People with Low Back Pain. Randomized Controlled Trial
}

Carolina Sandoval-Cuellar ( $\nabla$ carolinasandoval@uniboyaca.edu.co)

Universidad de Boyaca Facultad de Ciencias de la Salud https://orcid.org/0000-0003-1576-4380

Margareth Lorena Alfonso-Mora

Universidad de La Sabana

Adriana Lucia Castellanos-Garrido

Universidad de La Sabana

Angélica del Pilar Villarraga-Nieto

Universidad de La Sabana

Ruth Liliana Goyeneche-Ortegón

Universidad de Boyaca Facultad de Ciencias de la Salud

Martha Lucia Acosta-Otalora

Universidad de La Sabana

Rocio del Pilar Castellanos-Vega

Universidad de Boyaca Facultad de Ciencias de la Salud

Elisa Andrea Cobo-Mejía

Universidad de Boyaca Facultad de Ciencias de la Salud

Research article

Keywords: simulation, physiotherapy, clinical skill, simulated patient

Posted Date: January 8th, 2021

DOI: https://doi.org/10.21203/rs.3.rs-32849/v2

License: (9) (7) This work is licensed under a Creative Commons Attribution 4.0 International License. Read Full License

Version of Record: A version of this preprint was published at BMC Medical Education on July 9th, 2021. See the published version at https://doi.org/10.1186/s12909-021-02812-7. 


\section{Abstract}

Background: Low back pain (LBP) is a symptomatology with a high global prevalence; health professionals, including physiotherapists, must have the skills to create professional actions that increase a quality of life for patients. Clinical simulation can be a pedagogic strategy that facilitates in students adequate training to acquire skills that improve professional reasoning in this clinical situation. The objective of this study was to compare the effects of clinical simulation with simulated patient (SP) versus simulation with role playing (RP) in physiotherapy students for decision-making in clinical skills while caring for a person with LBP.

Methods. Experimental study, with 42 participants from two Colombian universities, randomized into two groups $(\mathrm{SP} n=21, \mathrm{RP} n=21)$. The clinical skill was evaluated during the interaction with a person with LBP for which the Objective Structured Clinical Examination (OSCE-LBP) was validated for individuals with low back pain; thereafter, a pedagogical method was conducted that included clinical simulation and, finally, the OSCE-LBP was applied again to compare both groups.

Results. Changes occurred in the OSCE-LBP among both groups of students: the scores increased ( 0.66 and 0.59 in RP and SP, respectively), and neither of the two was superior (difference $0.0195 \% \mathrm{Cl}-0.21$ to 0.23 ).

Conclusion. Both types of simulation favour decision-making in professional reasoning in physiotherapy students during interaction with individuals with LBP.

Contribution of paper: This is an RCT that explores the use of clinical simulation with simulated patient as a teaching method in decision making by physiotherapists versus traditional use of role playing

\section{Background}

Low back pain (LBP) is one of the principal reasons for consulting health services globally $(1,2)$. Epidemiological reports state that the incidence of this symptomatology is between $60 \%$ and $90 \%$ in the Western population, affecting almost $80 \%$ of people at least once in their lives (3). LBP is considered one of the principal causes of absenteeism and the risks associated with it are diverse, including lifestyle, work and emotional factors, among others $(3,4)$. In physiotherapy, it is the most frequent reason for care, which is why professionals must have the necessary skills to offer those people who consult them a comprehensive approach that minimizes reoccurrence and improves their quality of life. To achieve this, it is necessary for programmes in physiotherapy to provide sufficient tools to enable future professionals to have the skills to interact with people with LBP.

For this interaction, physiotherapists must: 1) perform physiotherapeutic examinations and evaluation that include Interview, standardized systems review, and the selection and application of tests and measurements; 2) discuss the examination findings, supported by professional reasoning; 3 ) formulate physiotherapeutic diagnosis and prognosis in line with the findings obtained; 4) provide information to patients about a treatment plan according to the examination findings; 5.) execute the treatment plan supported by scientific evidence; and 6) demonstrate humanized treatment and communication skills during the physiotherapeutic interaction (5).

Each of these elements is related to clinical skills for decision-making regarding physiotherapeutic practice as a basis for the development of a professional abilities and skills (6), such as professional reasoning supported by knowledge and values originating from high levels of quality focused on caring for patients (7). This is a process of application of integrated knowledge that includes intuition and permits timely development of examinations or physiotherapeutic interventions (7), through constant reflection during professional interactions.

Simulation can be used as a pedagogic tool that provides students with significant learning regarding decision-making in interacting with people, in this case patients with LBP. It is a potential strategy for developing diverse skills focused on the safety of the patient and the therapist (8). Moreover, it permits the inclusion of simulated patients (9); these are people who receive training in representing a specific health condition with a view to generating teaching or evaluation processes in interpersonal and/or clinical skills (10). Simulations with simulated patients give students an authentic learning experience (10) and, given their closeness to the real scenarios, facilitate effective identification of student performance.

Clinical simulation allows students to get involved in direct interaction with what they are studying, rather than an intellectual observation or description, and enables them to make significant progress in their development through their own experience (11). The World Confederation for Physical Therapy (WCPT) states that students must be guaranteed opportunities for clinical interaction, which should always be accompanied by qualified professionals. Simulations may be linked to this process, given that controlled scenarios promote clinical reasoning, and theoretical information can be used to consolidate learning (12).

The evidence around simulation suggests that this is an educational strategy that increases teamwork capabilities and it should be aligned with the principles of Interprofessional education $(13,14)$. The simulation also promotes core values, communication skills among professionals and with the patients, and patient safety (15-18). Simulation in physiotherapy has been used in a large way for cardiorespiratory practice for training specific manual skills and decision-making processes in intensive unit care. Students that have been trained with this pedagogic strategy give more safety to the patients and get better results in manual and instrumental procedures in general (19-25). 
The education-based in simulation has demonstrated students improve "confidence in clinical skills, clinical decision-making, treatment preparation and planning, communication skills, evaluating and modifying interventions, and interprofessional practice"(26).

This study used simulation with standardized patient generating a controlled scenario with a person manifesting LBP, seeking to use the knowledge acquired to make clinical decisions and respond to the needs of people with a health condition framed within a particular context. Thus, the aim of this study was to determine the effects of clinical simulation with standardized patients on physiotherapy students regarding decision-making on clinical skills while caring for a person with LBP.

\section{Methods}

\section{Design}

A randomized controlled trial was performed with formulation of equivalence with physiotherapy students from two Colombian universities. The students were randomized into two groups, SP and RP, to compare the effects of both types of pedagogic intervention supported by clinical simulation. The study was approved by the ethics committee at the University of Boyacá under record number 164 of 09 June 2016, and by the subcommission on research and ethics at University of La Sabana; it was considered of minimum risk and the students were assured that the research process would not affect their semester grades; hence, the evaluations were of a formative nature.

\section{Subjects}

The study included 42 fifth-semester students from two physiotherapy programmes in two Colombian universities, based on the formula for equivalency trials (27), in which size per group; normal two-tail standard deviation; acceptable difference; = standardized standard deviation of both comparison groups.

$$
n=2 \frac{\left[\left(Z_{1-\frac{\alpha}{2}}+Z_{\beta}\right)^{2}\right]}{d^{2}} s^{2}
$$

At the time of the study, the participants had taken a total of 87 credits and were actively enrolled in the participating programmes. The study excluded students $<18$ age, those who had been internally or externally transferred from another academic programme in health, exchange students, and those repeating and with prior experiences in simulated practice in other assignments.

The study established a stratified sampling by blocks in each university by using the Epidat program version 3.1 and assigning participants to one of the SP and RP groups, a procedure overseen by a professor not involved with the study. A record of the process was kept (Figure 1).

\section{Result measurements}

The study took into consideration the variables of gender, percentage of attendance of academic activities in SP and RP, level of bilingualism, score on the Colombian "SaberPro" state examination, and participants' accumulated academic grade point average for their undergraduate formation.

The main outcome of this randomized control trial was Objective Structured Clinical Examination for low back pain (OSCE-LBP). It was applied in al blinded way at the start (week 0 ) and end of the period of the SP and RP interventions (week 8). This instrument was subjected to a content validity process with external experts in the study area (28). Application of the OSCE-LBP, as an evaluation process, was conducted by external professors to the research process to minimize evaluation bias. Training of the human resources applying the OSCE-LBP was carried out through systematic training in developing the OSCE-LBP in its different stages. Additionally, inter-rater correlation coefficient values were obtained (28), and the stages in which the professors had their best performance was identified compared with the denominated gold-standard evaluator (29).

The OSCE-LBP evaluates decision-making in clinical skills while caring for a person with LBP. It has seven stages each with a specific weight, assesses the skills or abilities described by the researchers regarding physiotherapeutic decision-making for a person with LBP, thus:

1) Physiotherapeutic examination (stage 1,2 and 3)

I. Anamnesis: recognizes the symptoms or antecedents including red flags and personal aspects that can guide decision making by physiotherapists in relation to LBP.

II. Revision by systems: recognizes physical symptoms that indicate red flags or signs of peripheral nerve involvement, or signs of LBP.

III. Tests and measurements: applies tests and measurements related to mobility, articular integrity, strength of the lumbo-pelvic complex, and the integrity of the peripheral nerves of the lumbo-pelvic region.

2) Physiotherapeutic evaluation (stage 4) 
I. Explains to a person with LBP whether their condition is related to nociceptive LBP, neuropathic LBP or another type (central sensitization).

3) Diagnosis, prognosis and intervention plan (stage 4)

I. Proposes reachable objectives according to the characteristics of the person's LBP.

II. Provides information to the patient about the treatment plan to follow according to findings obtained in the examination related with LBP prognosis.

III. Is clear with the language used and in line with previous aspects of the interaction process.

4) Intervention (stage 5, 6 and 7)

I. Includes therapeutic exercise according to the person's needs and capacity.

II. Includes manual techniques according to the needs.

III. Includes specific physiotherapy techniques according to the needs.

IV. Includes interpretation of scientific evidence that supports the decision-making process (30-36).

5) Demonstrates patient centered-care and communication skills during the process of professional interaction (all stages).

I. Verbal, proxemic, paralinguistic and assertive tactile communication is demonstrated according to the performance context.

The results method of scoring the OSCE-LBP was established on a scale from 0.0 to 5.0 . This scoring was obtained with a specific weight for each stage. It was given by a research team in percentages as shown: stage 1: $17 \%$, stage 2 : $12 \%$ Stage $3: 16 \%$, stage 4 : $15 \%$, stage 5 : $15 \%$, stage $6: 13 \%$, stage $7 \%$ : $12 \%$. An equivalency success was determined in the SP and RP interventions with a difference of 0.8 (37).

\section{Intervention}

For both groups, the same pedagogic process was established to achieve the skills related to the interaction with people with LBP (described using the OSCELBP) in the following manner:

I. Learning guide process of therapeutic interaction with a person with LBP. The guide was distributed two weeks prior to conducting the SP or RP; its intention was to serve as a facilitator of the following phases of the learning process. The guide was constructed by the research team including in its first part information and independent activities for students to carry out a retrospective search about physiotherapeutic examinations and treatment for people with LBP supported in scientific evidence.

II. Development of skills through laboratory workshops for the prescription and application of manual techniques and therapeutic exercise for the health condition studied. Each group had 10 hours of classroom sessions prior to the SP or RP, with each session seeking to develop the practical aspects of the learning guide, which in the manual techniques included therapeutic massage (30), and superficial techniques of myofascial release for paravertebral muscles and related to the lumbo-pelvic complex (38). The exercise techniques included central stabilization exercises (39), analytic stretching and principles of postural re-education (40).

III. Simulation activity: for group one with standardized patient was constructed supported by a high fidelity guides in simulation training, which for this study is denominated SP. Group two was RP, using a methodology of low fidelity simulation.

The group denominated SP received a teaching strategy based on a class session with simulated practice for decision-making in clinical skills when caring for a person with LBP. Each session lasted approximately 120 minutes, and the clinical case used for the SP sessions was subjected to face validity with experts in the area of study.

Application of the simulated practice was conducted based on experiential knowledge of high fidelity simulation training, considering the following sequence of its elements:

- Context of the scenario: standardized for a clinical scenario of external consultation for the care of a person with LBP using physiotherapy.

- Patient standardization: based on the clinical case elaborated and validated, a script was created for the actor to interpret a person with LBP. Three simulated patients were trained per institution and their participation had a ratio of one patient for every eight students.

- Professor facilitator: a ratio was established of one professor for every eight students, and as in the case established, interpreted by the simulated patient, the professor started by approaching the person who was the object of care by following the characteristics of clinical reasoning.

- Guiding questions: the professor asked guiding questions that sought to stir reflection regarding the clinical situation observed, asking students to imagine other clinical situations and how the intervention would vary according to this.

- Concrete experience: students were permitted to interact with the simulated patient to carry out the reasoning process and thus provide care to the person.

- Debriefing: a meeting was held based on reflective conversation about the learning experience in which all the actors discussed the positive aspects and the learning opportunities. This process was mediated by dialogue and active listening; at the center of it were the students, who reflected on what they 
had done, and described their feelings and emotions, what was opportune, and what they would improve for subsequent opportunities with a person with LBP, this kind of data was not used for the purpose of this study.

The RP group, in turn, received a class session based on a "role-playing" simulation strategy, structured for the same purpose established in the SP group. This session lasted approximately 120 minutes, and the learning environment was the classroom in which students assumed different roles to act out; some of them acted like people with LBP and others as physiotherapists. The rolling-playing strategy not included specific training for acting like a patient. The study cases used for the RP group were different from SP group but with a similar level of complexity in LBP. The sequence of elements taken into account in RP group was:

- Division of the student's group into two: 1) physiotherapist and 2) patients.

- Three different case study were given to students case 1 was about pregnancy LBP, case two posttraumatic LBP, case three about nonspecific LBP.

- Both groups of students starting the acting process like physiotherapists or patients.

- At the end of the simulation, the students guided by a professor closed the simulation with a conclusion for each case study, in a not extensive way like the debriefing process in SP group.

\section{Statistical analysis}

Baseline: determined the distribution of the variables (extreme values, symmetries, kurtosis, types of distribution) - for qualitative variables like gender, semester, University (table 1) were calculated relative frequencies (mode and erroneous data), and in all cases, evaluating the amount of data lost by each variable.

The quantitative variables like academic average over 5.0; credits taken according to Colombian educational system ( 1 credit equals to 48 hours per week in academic activities), bilingualism equal to the number of credits in the English language, and age in years. Those were described with a symmetric dispersion through medians and standard deviation.

To compare the effect of the magnitude, an analysis by intention to treat was performed. Initially, a difference of averages in the main outcome of the study OCSE between SP group and RP group. Also, was estimated the difference between the basal measurement and after the intervention. Thereafter, a comparison was made of the interventions through a two-level hierarchical model of random intercepts and fixed coefficients (level 2: university; level 1: subject). The model is described by the following.

$$
y_{i j}=\beta_{o}+\beta_{1} I G_{1 i j}+\beta_{2} B M_{2 i j}+U_{o j}+e_{i j}
$$

i: Individual, j: University, IG: Intervention Group, MB: Basal Measurement

Estimation of parameters was used with a 95\% confidence level. Analyses were carried out using STATA version 14.

\section{Results}

The participating population was mostly of female sex, with a mean age of 21 years, an academic average of 3.6 (over 5 ), and an average of 87 credits taken in the Physiotherapy programme at each university (Table 1).

Table 1. Characteristics of the participants

\begin{tabular}{|l|c|c|}
\hline Sex & $\begin{array}{c}\text { Role Playing (RP) } \\
\mathrm{n}=21\end{array}$ & Simulated Practice (SP) $\mathrm{n}=21$ \\
\hline Male & $7(33.4 \%)$ & $3(14.3 \%)$ \\
\hline Female & $14(66.6 \%)$ & $18(85.7 \%)$ \\
\hline University & & $12(57.1 \%)$ \\
\hline University of La Sabana & $9(42.9 \%)$ & $9(42.9 \%)$ \\
\hline University of Boyacá & $12(57.1 \%)$ & $21.6[2.3]$ \\
\hline & & $3.6[0.2]$ \\
\hline Age & $21.4[2.1]$ & $8.9[4.8]$ \\
\hline Academic average & $3.7[0.3]$ & $84.7[11.6]$ \\
\hline Bilingualism & $7.8[4.2]$ & \\
\hline Credits taken & $87.2[13.2]$ & \\
\hline $\begin{array}{c}\text { [ ] = average [standard deviation] } \\
\text { ( (\%) = absolute frequency (percentage) }\end{array}$ & & \\
\hline
\end{tabular}


The table 2 shows that in both RP and SP, the final score increases ( 0.66 and 0.59 in RP and SP, respectively); when comparing the interventions, it is noted that neither of the two was superior (difference $0.0195 \% \mathrm{Cl}-0.21$ to 0.23 ). The study reports $100 \%$ participant adherence.

Table 2 Comparing the interventions

\begin{tabular}{|c|c|c|c|c|c|c|c|c|c|c|}
\hline & \multicolumn{2}{|c|}{$\begin{array}{c}\text { Role Playing } \\
n=21\end{array}$} & \multicolumn{2}{|c|}{$\begin{array}{c}\text { Simulated Practice } \\
\mathrm{n}=21\end{array}$} & \multicolumn{2}{|c|}{ Difference in Role Playing } & \multicolumn{2}{|c|}{ Difference in Simulated Practice } & \multicolumn{2}{|c|}{ Difference in both interventions } \\
\hline & Baseline & Post-intervention & Baseline & Post-intervention & Diff. & $95 \%$ CI & Diff. & $95 \% \mathrm{CI}$ & Diff. & $95 \%$ CI \\
\hline Mean OSCE - LBP & $2.07[0.45]$ & $2.73[0.51]$ & $2.16[0.42]$ & $2.76[0.48]$ & -0.66 & -0.97 to -0.34 & -0.59 & -0.89 to -0.30 & 0.01 & -0.21 to 0.23 \\
\hline
\end{tabular}

\section{Discussion}

The study results reveal that pedagogic strategies supported by simulation improve clinical skills in interacting with people with LBP. Both types of simulation generated positive changes in the: 1) examination; 2) evaluation; 3) diagnosis; 4) prognosis; and 5) physiotherapeutic intervention. To date, publications have not been found using simulation to train physiotherapists to interact with people diagnosed with LBP, which could be a powerful tool for enhancing decisionmaking with respect to one of the primary reasons for consulting health services, and high-quality physiotherapy could be a solution for reducing the reoccurrence of this symptomatology.

Other clinical areas in which physiotherapists work have already demonstrated the positive effects of simulation as a pedagogic approach that develops integrally the skills of the future professional. Some antecedents mention that simulation improves teamwork and the understanding of professional roles (41); it can replace part of the time in clinical institutions (37), contribute to education in cardiorespiratory physiotherapy (20), improve confidence in students and enhance the procedural skills in the different performance areas (42).

For the specific case of performance skills in the musculoskeletal area, Wright et al., (2018) report that after a $100 \%$ immersion in clinical simulation for 18 days, students showed significant improvement in their confidence and, in general, in their performance in regard to the clinical approach to patients. The authors report that students who were exposed to rotations in simulated scenarios demonstrated a significantly higher performance in clinical skills than those who did not undergo this immersion.

The types of simulation used for this study were of high fidelity with the standardized patient for group SP and role-playing as a low fidelity scenario in group RP. According to the results, both types contributed to the integration of knowledge developed along the pedagogical process constructed to achieve the learning objectives related to the therapeutic interaction with a person with LBP. Respect to SP group, the potential benefit is that direct interaction with others with a specific training can create an environment quite close to the reality, which can become an alternative with effects comparable with conventional clinical practices (43). With respect to RP group, the literature also reports that it leads students to appropriate the characteristics of the subjects implied in the process and this facilitates integration of knowledge (44).

Although research on clinical simulation as a pedagogic strategy in physiotherapy has increased, it is necessary to continue with reports of this type to enhance student training in therapeutic interaction and thus improve decision-making in the clinical reality (45).

The pedagogic process with simulation in both groups (PS and RP) included other educational activities like literature review, retrospective searches about the examination of LBP, laboratory workshops, and classroom sessions. This aspect would be the main limitation of the present study cause improvement in the final OSCE-LBP assessment be related to these interventions and not just the simulation activity itself.

\section{Conclusion}

From the results herein, it may be stated the pedagogic process, including the simulation activity resulted in improved decision-making by the physiotherapy students during the process of professional reasoning regarding a person with LBP; as for the design proposed, equivalence is evidenced between both types of simulation, RP and SP.

\section{Practice Points}

- Physiotherapeutic reasoning training in Low Back Pain can be combined with simulation scenarios to increased learning enhancement.

- Rolling playing and simulation practice in physiotherapy are teaching strategies that can provide training for musculoskeletal disorders in practitioners of physiotherapy.

\section{Abbreviations}


LBP: Low back pain; SP: Clinical simulation with simulated patient; RP:

Simulation with role playing; OSCE-ML: Objective Structured Clinical Examination

\section{Declarations}

Ethics approval and consent to Participate: this study was approved by the ethical committee of clinical center Universidad de Boyaca in June of 2016 . The study included an informed consent signature in a writing way for all participants according to a Helsinki declaration and with 8430 Colombian law (1993).

Consent for publication: Not Applicable

Consent to publish: all authors have given their consent to publish this study

Availability of data and materials: the data collected is available in the public archive of the physiotherapy program of the Universidad de Boyaca.

Competing interests: the authors declare not have conflict of interest about this manuscript.

Funding: This study was funded by the Universidad de La Sabana, Universidad de Boyaca and the Colombian Association of Physiotherapy Faculties (known as ASCOFAFI in Spanish). Universities mentioned above developed the role of design, data recollection, outcome analysis, and results divulgations included writing manuscript. ASCOFAFI founded the data recollections activities

Authors Contributions: MLAM, CSC, ADPV, and RPCV were responsible for the design of the study. EACM, RLGO, and MLAO gave advice on assessment, viability, and intervention process respectively, all of them contribute to the research paper writing and have read and approved the manuscript.

Acknowledgements: The authors thank the students who participated as subjects of the experiment and professors who collaborated in the blind evaluation processes, as well as the University of La Sabana, the University of Boyacá that allowed the application in their facilities and the Colombian Association of Physiotherapy Faculties (known as ASCOFAFI in Spanish) as a funder of research processes.

\section{References}

1. Hartvigsen J, Hancock MJ, Kongsted A, Louw Q, Ferreira ML, Genevay S, et al. What low back pain is and why we need to pay attention. Lancet. 2018;6736(18):1-12.

2. Maher C, Underwood M, Buchbinder R. Non-specific low back pain. Lancet. 2017 Feb 18;389(10070):736-47.

3. Delgado JÁG, Lara GV, Torres J del CM, Morales IP. Epidemiología del dolor de espalda bajo. Investig Medicoquirúrgicas [Internet]. 2014;6(1):112-25. Available from: http://www.revcimeq.sld.cu/index.php/imq/article/view/275

4. Palomino Aguado B, Jiménez Cosmes L, Ferrero Méndez A. El dolor lumbar en el año 2009. Rehabilitacion. 2010;

5. American Physical Therapy Associactions. Guide to Physical Therapist Practice. November 2016.

6. ASCOFI, ASCOFAFI, COLFI A. Perfil profesional y Competencias del fisioterapeuta en Colombia [Internet]. Bogotá, Colombia; 2015 [cited 2018 May 11$].$ Available from: http://colfi.co/files/perfilProfesionalCompetencias.pdf

7. Atkinson HL, Nixon-Cave K. A tool for clinical reasoning and reflection using the international classification of functioning, disability and health (ICF) framework and patient management model. Phys Ther [Internet]. 2011;91(3):416-30. Available from:

http://linkinghub.elsevier.com/retrieve/pii/S0735675710005814\%5Cnhttp://www.ncbi.nlm.nih.gov/pubmed/21273627\%5Cnhttp://www.ncbi.nlm.nih.gov/

8. Acosta M, Alfonso M, Castellanos A, Castellanos P, Cobo E, Goyeneche R, et al. Simulación clínica una experiencia en fisioterapia. Sabana U de La, editor. Chía; 2020. 144 p.

9. Phillips AC, Mackintosh SF, Bell A, Johnston KN. Developing physiotherapy student safety skills in readiness for clinical placement using standardised patients compared with peer-role play: A pilot non-randomised controlled trial. BMC Med Educ. 2017;

10. Ruiz-Moral R, Caballero-Martínez F. Programa para seleccionar y entrenar pacientes estandarizados en el contexto de un currículo universitario de simulación clínica. FEM Rev la Fund Educ Médica. 2015;

11. Ariza MR. El Aprendizaje Experiencial Y Las Nuevas Demandas Formativas. Rev Antropol Exp. 2010;8:89-102. 
12. World Confederation for Physical Therapy. Policy statement: Education WCPT [Internet]. 2017 [cited 2018 Dec 11]. Available from: https://www.wcpt.org/policy/ps-education

13. Van Wyk R, Labuschagne MJ, Joubert G. Simulation as an educational strategy to deliver interprofessional education. African J Heal Prof Educ. 2020;12(2):74-80.

14. Brack P, Shields N. Short duration clinically-based interprofessional shadowing and patient review activities may have a role in preparing health professional students to practice collaboratively: a systematic literature review. J Interprof Care. 2019;33(5).

15. Seefeldt TM, Mort JR, Brockevelt B, Giger J, Jordre B, Lawler M, et al. A pilot study of interprofessional case discussions for health professions students using the virtual world Second Life. Curr Pharm Teach Learn [Internet]. 2012 Oct [cited 2017 Jun 12];4(4):224-31. Available from: http://linkinghub.elsevier.com/retrieve/pii/S1877129712000470

16. Sabus C, Sabata D, Antonacci D. Use of a virtual environment to facilitate instruction of an interprofessional home assessment. Allied Heal. 2011;40(4):199-205.

17. Hayward LM, Blackmer B, Markowsky A. Standardized Patients and Communities of Practice: A Realistic Strategy for Integrating the Core Values in a Physical Therapist Education Program. Journal, Phys Ther Educ. 2006;20(2):29-37.

18. Hayward LM, Blackmer B, Hayward L. A Model for Teaching and Assessing Core Values Development in Doctor of Physical Therapy Students. Jopte. 2010;24(3):16-26.

19. Marchal L, Barthod C, Goujon L, B??ssing T. Design and development of a mechatronic infant torso simulator for respiratory physiotherapy learning. Mechatronics. 2011;22(1):55-64.

20. Blackstock FC, Watson KM, Morris NR, Jones A, Wright A, McMeeken JM, et al. Simulation can contribute a part of cardiorespiratory physiotherapy clinical education: Two randomized trials. Simul Healthc. 2013;

21. Ohtake PJ, Lazarus M, Schillo R, Rosen M, Bourdin G, Barbier J, et al. Simulation experience enhances physical therapist student confidence in managing a patient in the critical care environment. Phys Ther [Internet]. 2013;93(2):216-28. Available from: http://www.ncbi.nlm.nih.gov/pubmed/23329555

22. Silberman NJ, Panzarella KJ, Melzer BA. Using human simulation to prepare physical therapy students for acute care clinical practice. $\mathrm{J}$ Allied Health. 2013;42(1):25-32.

23. Shoemaker MJ, Riemersma L, Ron P. Use of High Fidelity Human Simulation to Teach Physical Therapist Decision-Making Skills for the Intensive Care Setting. Cardiopulm Phys Ther J. 2009;20(1):13-8.

24. Gough, A. Y, P. R, J. M. Facilitating error recognition and patient safety awareness in pre-registration physiotherapy students using video reflexive ethnography and simulation-based education [Internet]. Vol. 101, Physiotherapy (United Kingdom). 2015. p. eS473. Available from:

http://ovidsp.ovid.com/ovidweb.cgi?T=JS\&PAGE=reference\&D=emed13\&NEWS=N\&AN=72114202

25. Smith N, Prybylo S, Conner-Kerr T. Using simulation and patient role play to teach electrocardiographic rhythms to physical therapy students. Cardiopulm Phys Ther J [Internet]. 2012;23(1):36-42. Available from: http://www.pubmedcentral.nih.gov/articlerender.fcgi? artid=3286499\&tool=pmcentrez\&rendertype=abstract

26. Hough J, Levan D, Steele M, Kelly K, Dalton M. Simulation-based education improves student self-efficacy in physiotherapy assessment and management of paediatric patients. BMC Med Educ. 2019;19(1):1-11.

27. Zhong B. How to calculate sample size in randomized controlled trial? J Thorac Dis. 2009;1(1):51-4.

28. Carvajal A, Centeno C, Watson R, Martínez M, Sanz Rubiales A. How is an instrument for measuring health to be validated?. An Sist Sanit Navar [Internet]. 2011;34:63-72. Available from: http://www.ncbi.nlm.nih.gov/pubmed/21532647

29. Campo-Arias A, Herazo E. Concordancia intra- e interevaluadores. Rev Colomb Psiquiat. 2010;39(2):424-32.

30. Furlan AD, Imamura M, Dryden T, Irvin E. Massage for low back pain: An updated systematic review within the framework of the cochrane back review group. Spine (Phila Pa 1976). 2009;

31. Rubinstein SM, van Middelkoop M, Assendelft WJ, de Boer MR, van Tulder MW. Spinal manipulative therapy for chronic low-back pain. Cochrane Database Syst Rev [Internet]. 2011 Feb 16 [cited 2018 Nov 21];(2). Available from: http://doi.wiley.com/10.1002/14651858.CD008112.pub2

32. Parreira P, Heymans MW, van Tulder MW, Esmail R, Koes BW, Poquet N, et al. Back Schools for chronic non-specific low back pain. Cochrane Database of Systematic Reviews. 2017.

33. Engers AJ, Jellema P, Wensing M, van der Windt DA, Grol R, van Tulder MW. Individual patient education for low back pain. Cochrane Database Syst Rev [Internet]. 2008 Jan 23 [cited 2018 Nov 21];(1). Available from: http://doi.wiley.com/10.1002/14651858.CD004057.pub3

34. French SD, Cameron M, Walker BF, Reggars JW, Esterman AJ. Superficial heat or cold for low back pain. Cochrane Database Syst Rev [Internet]. 2006 Jan 25 [cited 2018 Nov 21];(1). Available from: http://doi.wiley.com/10.1002/14651858.CD004750.pub2

35. Whitehead A, Gould Fogerite S. Yoga Treatment for Chronic Non-Specific Low Back Pain (2017). Explor J Sci Heal. 2017;

36. Hayden JA, Van Tulder MW, Malmivaara A V., Koes BW. Meta-analysis: Exercise therapy for nonspecific low back pain. Annals of Internal Medicine. 2005.

37. Blackstock FC, Watson KM, Morris NR, Jones A, Wright A, McMeeken JM, et al. Simulation Can Contribute a Part of Cardiorespiratory Physiotherapy Clinical Education. Simul Healthc J Soc Simul Healthc [Internet]. 2013;8(1):32-42. Available from: http://content.wkhealth.com/linkback/openurl? sid=WKPTLP:landingpage\&an=01266021-201302000-00007

38. Pilat A. Terapias Miofasciales: Induccion Miofascial. Mcgraw-Hill Interamericana De España S.L., editor. 2003.

39. Wang XQ, Zheng JJ, Yu ZW, Bi X, Lou SJ, Liu J, et al. A Meta-Analysis of Core Stability Exercise versus General Exercise for Chronic Low Back Pain. PLoS One. 2012; 
40. Paolucci T, Attanasi C, Cecchini W, Marazzi A, Capobianco S V., Santilli V. Chronic low back pain and postural rehabilitation exercise: A literature review. Journal of Pain Research. 2019.

41. Dennis D, Furness A, Duggan R, Critchett S. An Interprofessional Simulation-Based Learning Activity for Nursing and Physiotherapy Students. Clin Simul Nurs. 2017;

42. Wright A, Moss P, Dennis DM, Harrold M, Levy S, Furness AL, et al. The influence of a full-time, immersive simulation-based clinical placement on physiotherapy student confidence during the transition to clinical practice. Adv Simul. 2018;

43. Pritchard SA, Blackstock FC, Nestel D, Keating JL. Simulated patients in physical therapy education: Systematic review and meta-analysis.(Research Report). Phys Ther. 2016;96(9):1342.

44. Brauer $\mathrm{S}$ et al. Proceedings of the Australian and New Zealand Association for Health Professional Educators. In: mproving clinical preparation, communication, confideence and satisfaction in physiotherapy students through role-playing [Internet]. Launceston; 2009. p. 84. Available from: 363deb_79ff928b56431c1d4bb61d35d17711ff

45. Judd BK, Scanlan JN, Alison JA, Waters D, Gordon CJ. The validity of a professional competence tool for physiotherapy students in simulation-based clinical education: A Rasch analysis. BMC Med Educ. 2016;

\section{Figures}

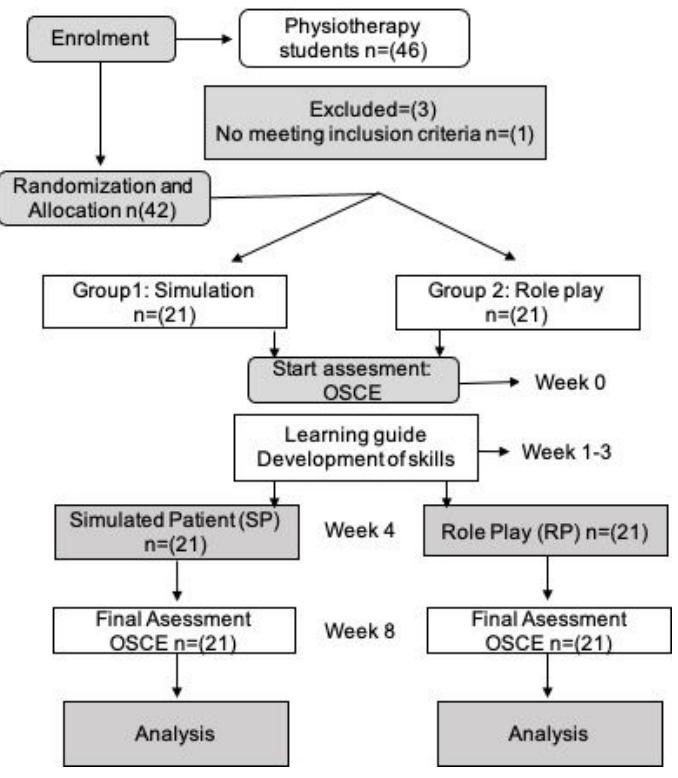

Figure 1

Flow diagram of the study "Simulated practice in physiotherapy students from the University of Boyacá and University of La Sabana on decision-making in clinical skills while caring for a person with LBP”. Intervention group: Simulated practice; control group: "Role playing". 